\title{
Beta-Lactamase Production in Staphylococcus Aureus from Urine of Symptomatic and Asymptomatic Subjects in Keffi, Nigeria
}

\author{
*11Ngwai, Y.B., ${ }^{1}$ Nkene, I.H., ${ }^{2}$ Hussain U.K., ${ }^{1}$ Abimiku R.H., ${ }^{1}$ Darda'u, A.A., \\ ${ }^{1}$ Okposhi, I.I
}
${ }^{1}$ Microbiology Unit, Department of Biological Sciences, Nasarawa State University, Keffi, Nigeria
${ }^{2}$ Department of Pharmaceutics and Pharmaceutical Microbiology, Faculty of Pharmaceutical
Sciences, Usmanu Danfodiyo University, Sokoto, Nigeria
*ngwaiyb@yahoo.com

\begin{abstract}
Staphylococcus aureus is a common pathogen associated with urinary tract infection. The production of beta-lactamase by $S$. aureus from urine of symptomatic and asymptomatic subjects in Keffi, Nigeria was investigated. Urine samples were collected from patients with suspected cases of urinary tract infection (UTI) attending two health facilities in Keffi; and asymptomatic volunteering students, staff and others within and around the Nasarawa State University Keffi main campus. Staphylococcus aureus were isolated from the urine samples using standard cultural, microscopical and biochemical methods. Antibiotic susceptibility testing and minimum inhibitory concentration (MIC) were evaluated as described by the Clinical and Laboratory Standards Institute (CLSI). Beta-lactamase production was evaluated by iodometric methods. A total of hundred (100) isolates (50 symptomatic, 50 asymptomatic) were isolated from the urine samples. Symptomatic isolates had susceptibility which decreased as follows: streptomycin (86\%) > gentamicin (84\%) and erythromycin $(84 \%)>$ rifampicin $(80 \%)>$ norfloxacin $(78 \%)>$ amoxicillin $(70 \%)$ and chloramphenicol $(70 \%)>$ levofloxacin $(68 \%)>$ ciprofloxacin $(60 \%)>$ ampicillin (58\%). Asymptomatic isolates had susceptibility which decreased as follows: gentamicin (92\%), streptomycin (92\%) and rifampicin (92\%) > erythromycin $(88 \%)>$ ciprofloxacin $(84 \%)>$ levofloxacin $(80 \%)>$ norfloxacin $(78 \%)>$ chloramphenicol $(76 \%)>$ amoxicillin $(72 \%)$ and ampicillin (72\%). The differences in the susceptibility of symptomatic and asymptomatic isolates to the antibiotics tested were insignificant $(p>0.05)$. The MICs of amoxicillin against amoxicillin resistant $S$. aureus isolates for $50 \%$ and $90 \%$ of for symptomatic isolates were $\leq 8 \mu \mathrm{g} / \mathrm{ml}$ and $\leq 16$ $\mu \mathrm{g} / \mathrm{ml}$ respectively; for asymptomatic isolates, the MICs for $50 \%$ and $90 \%$ isolates were $\leq 34 \mu \mathrm{g} / \mathrm{ml}$ and $\leq 64$ $\mu \mathrm{g} / \mathrm{ml}$ respectively. Beta-lactamase was detected in $4(23.5 \%)$ and 5 (35.7\%) of amoxicillin resistant symptomatic and asymptomatic isolates respectively. Molecular characterization of beta-lactamase genes in these amoxicillin resistant $S$. aureus isolates from Keffi is on-going.
\end{abstract}

Keyword: Staphylococcus aureus, Antibiotic Susceptibility; Beta-lactamase; Symptomatic; Asymptomatic; Urine.

\section{INTRODUCTION}

Urinary tract infection (UTI) is a notorious problem in both the community and hospital practices, affecting people of all ages and gender (Adeleke and Olarinde, 2013; Al-Jumaily et al., 2012; SalemBekhit, 2014). Staphylococcus aureus has been reported as one of the etiological agents associated with UTIs that is commonly isolated from urine of both symptomatic and asymptomatic subjects (Demuth, 1979).

Before the introduction of penicillin in 1940, patients with S. aureus infection had a mortality of 90\%; with the advent of penicillin era, remarkable improvement was observed in the recovery and survival of infected patients (Shrestha et al., 2014). This historic triumph, however, was relatively short-livednot too long after the introduction of penicillin in clinical use, due to the development of resistance to penicillin by $S$. aureus. Resistance mechanisms include enzymatic inactivation of the antibiotic (penicillinase and aminoglycoside-modification enzymes), alteration of the target with decreased affinity for the antibiotic (notable examples being penicillin-binding protein $2 \mathrm{a}$ of methicillin-resistant S. aureus and D-Ala-D-Lac of peptidoglycan precursors of vancomycin-resistant strains), trapping of the antibiotic (for vancomycin and possibly daptomycin) and efflux pumps (fluoroquinolones and tetracycline) (Pantosti et al., 2007).

Beta-lactamase production is a major mechanism by which $S$. aureus develops resistance to betalactam antibiotics (Akindele et al., 2010). The beta-lactamase enzymes produced by $S$. aureus confer 
resistance against beta-lactam antibiotics like penicillin; and are encoded in the blaZ gene located on a transposable part of the large plasmid within the $S$. aureus bacterial cells (Hugo and Russel, 1986; Shrestha et al., 2014). Because of its location, the gene is easily movable to surrounding cells through horizontal gene transfer.

In Nigeria, there are few reports of beta-lactamase mediated $S$. aureus resistance in human isolates (Olowe et al., 2007; Akindele et al., 2010; Atata et al., 2013; Torimiro et al., 2013). This study aimed at isolation of beta-lactamase producing $S$. aureus from urine of symptomatic and asymptomatic subjects in Keffi, Nigeria. Detection of the resistance mechanisms and their genetic basis is an important support to antibiotic susceptibility surveillance in S. aureus.

\section{Materials ANd Methods}

\subsection{Materials}

Media used were: Mannitol Salt Agar (MSA: Oxoid LTD, Basingstoke, Hamphire, England), Nutrient Agar (NA: Oxoid LTD, Basingstoke, Hamphire, England), Mueller-Hinton Agar (MHA: Oxoid LTD, Basingstoke, Hamphire, England) and Mueller-Hinton Broth (MHB: Oxoid LTD, Basingstoke, Hamphire, England). The media was prepared in accordance with manufacturer's instruction.

Chemicals and Reagents used include: Hydrogen peroxide (Sigma-Aldrich Laborchemikalien GmbH), Ethanol (Sigma-Aldrich Laborchemikalien $\mathrm{GmbH}$ ), $\mathrm{Na}_{2} \mathrm{HPO}_{4}$ (Encor Biotechnology Inc. Gainsville, Florida), Magnesium Sulphate (Nen Tech Ltd, United Kingdom), Phenol Red (HiMedia Laboratories, Marg, Mumbai, India), $\mathrm{NaHCO}_{3}$, Calcium Chloride (BDH Laboratory supplies, Poole, BHIS Ltd, United Kingdom), Iodine reagent (HiMedia Laboratories, Marg, Mumbai, India), Potassium Chloride (BDH Laboratory supplies, Poole, BHIS Ltd, United Kingdom) and Potassium Iodide and soluble Starch (HiMedia Laboratories, Marg, Mumbai, India).

The antibiotic discs used were products of Optun Lab. Ltd (Nigeria); and include: Ciprofloxacin (10 $\mu \mathrm{g})$, Norfloxacin $(10 \mu \mathrm{g})$, Gentamicin $(10 \mu \mathrm{g})$, Amoxicillin $(20 \mu \mathrm{g})$, Streptomycin (30 $\mu \mathrm{g})$, Rifampicin $(20 \mu \mathrm{g})$, Erythromycin $(30 \mu \mathrm{g})$, Chloramphenicol $(30 \mu \mathrm{g})$, Ampicillin $(20 \mu \mathrm{g})$ and Levofloxacin $(20$ $\mu \mathrm{g}$ ). Benzylpenicillin (Britannia Pharmaceutical, United Kingdom) and amoxicillin (Uttar Pradesh, India) injection powders were purchased from Pharmacy Department Federal Medical Centre, Keffi, Nigeria.

\subsection{Study Area and Sample Collection}

This study was carried out in Keffi metropolis. Keffi is about $53 \mathrm{~km}$ away from the Federal Capital Territory, Abuja and $137 \mathrm{Km}$ away from Nasarawa State Capital, Lafia. Keffi is located at Longitude $8^{\prime} 5^{\circ} \mathrm{S}$ (South) and Latitude $7^{\prime} 5^{\circ} \mathrm{N}$ (North) and is $630 \mathrm{~m}$ above sea level (Akwa et al., 2007).

A total of 200 urine samples were collected- 100 from patients with UTI symptoms attending Federal Medical Center, Keffi and South Atlantic Petroleum Medical Center, Nasarawa State University, Keffi; 100 from volunteering asymptomatic students, staff and others within and around Nasarawa State University, Keffi. The samples were transported to Microbiology Laboratory, Nasarawa State University, Keffi for analysis.

\subsection{Isolation of Staphylococcus aureus}

Staphylococcus aureus was isolated from the urine of asymptomatic subjects as follows: a loopful of urine was streaked on MSA plate and incubated at $37^{\circ} \mathrm{C}$ for $24 \mathrm{~h}$. Golden yellow colonies that grew on MSA were presumptively selected as $S$. aureus.

\subsection{Identification of Staphylococcus aureus}

The presumptive $S$. aureus was further confirmed by Gram staining of the golden yellow colonies from MSA and minimal biochemical tests for S. aureus identification (catalase, coagulase) as earlier described (Cheesbrough, 2006).

\subsection{Antibiotic Susceptibility Testing}

Antibiotic susceptibility testing of the bacterial isolates was carried out using Kirby-Bauer disk diffusion method as modified by Clinical and Laboratory Standards Institute (CLSI, 2014). Briefly four (4) colonies of the isolates were transferred into $5 \mathrm{ml}$ of sterile normal saline $(0.9 \mathrm{~g} \mathrm{NaCl}$, distilled water to $100 \mathrm{ml}$ ) in a tube such that the turbidity of the bacterial suspension was equivalent to 
Beta-Lactamase Production in Staphylococcus Aureus from Urine of Symptomatic and Asymptomatic Subjects in Keffi, Nigeria

0.5 McFarland Standard. The sterile swab was dipped in the bacterial suspension and streaked on MHA and each antibiotic disc was aseptically placed with a sterile pair of forceps on the surface of the inoculated MHA plate. The plate was incubated at $37^{\circ} \mathrm{C}$ for $24 \mathrm{~h}$. The diameter of the zone of inhibition was measured using meter rule and the result was interpreted in accordance with the susceptibility break point as earlier described (CLSI, 2014).

\subsection{Determination of Minimum Inhibition Concentration}

The MICs of amoxicillin against amoxicillin resistant $S$. aureus were evaluated using the agar dilution method in accordance with the guidelines by the Clinical and Laboratory Standards Institute (CLIS, 2014). Briefly, two-fold concentration agar dilutions of ceftazidime or cefotaxime in MHA were prepared and inoculated with approximately $1 \times 10^{4}$ colony-forming units (CFU) from an adjusted suspension of a test organism. Results were observed and registered after incubation at $37^{\circ} \mathrm{C}$ for $24 \mathrm{~h}$. MIC was defined as the lowest concentration that inhibited visible growth.

\subsection{Detection of $\beta$-Lactamase Production}

The detection of beta-lactamase production by amoxicillin resistant $S$. aureus was carried out using iodometric following a method described by Atata et al. (2013). Briefly, some colonies of amoxicillin resistant $S$. aureus isolates were streaked on Nutrient agar plates containing $2 \%(\mathrm{w} / \mathrm{v})$ soluble starch and incubated at $37^{\circ} \mathrm{C}$ for $24 \mathrm{~h}$ and the overnight agar surface was flooded with freshly prepared $10,000 \mathrm{unit} / \mathrm{ml}$ of Penicillin G $(0.06 \mathrm{mg} / \mathrm{ml}$ in $0.1 \mathrm{M}$ phosphate buffer, $\mathrm{pH} 7.0)$ and left for $15-60 \mathrm{~min}$ at room temperature. Thereafter, iodine solution was added. Isolates whose colonies turned blue-black with colorless halos were considered as beta-lactamase producing isolates.

\subsection{Statistical Analyses}

The data obtained from this study were analyzed by One way Analysis of Variance (ANOVA) using Smith Statistical Package (SSP), version 2.8 (September 26, 2005, copyright (1995-2005 by Gary Smith, Pomona College, Claremont, California); and the significance of differences was determined at $5 \%$ probability.

\section{Results}

\subsection{Antibiotic Susceptibility}

The antibiotic susceptibilities of $S$. aureus isolates from urine of symptomatic and asymptomatic subjects are as shown in Table 1. Susceptibility of symptomatic isolates decreased as follows: streptomycin $(86 \%)>$ gentamicin $(84 \%)$ and erythromycin $(84 \%)>$ rifampicin $(80 \%)>$ norfloxacin $(78 \%)>$ amoxicillin $(70 \%)$ and chloramphenicol $(70 \%)>$ levofloxacin $(68 \%)>$ ciprofloxacin $(60 \%)$ $>$ ampicillin (58\%). Susceptibility of asymptomatic isolates decreased as follows: streptomycin $(92 \%)$, rifampicin $(92 \%)$ and gentamycin $(92 \%)>$ erythromycin $(88 \%)>$ ciprofloxacin $(84 \%)>$ levofloxacin $(80 \%)>$ norfloxacin $(78 \%)>$ chloramphenicol $(76 \%)>$ amoxicillin $(72 \%)$ and ampicillin (72\%). The differences in the susceptibilities between symptomatic and asymptomatic isolates were insignificant $(\mathrm{p}>0.05)$.

Table1. Antibiotic susceptibility of Staphylococcus aureus isolates from urine of symptomatic and asymptomatic subjects in Keffi, Nigeria

\begin{tabular}{|l|c|c|c|}
\hline Antibiotics & $\begin{array}{c}\text { Disc Content } \\
(\boldsymbol{\mu g})\end{array}$ & \multicolumn{2}{|c|}{ No. (\%) susceptibility of S. aureus } \\
\cline { 2 - 4 } & & $\begin{array}{c}\text { Symptomatic } \\
(\mathbf{n = 5 0 )}\end{array}$ & $\begin{array}{c}\text { Asymptomatic } \\
(\mathbf{n = 5 0})\end{array}$ \\
\hline Ciprofloxacin (CPX) & 10 & $30(60)$ & $42(84)$ \\
\hline Norfloxacin (NB) & 10 & $39(78)$ & $39(78)$ \\
\hline Gentamycin (GN) & 10 & $42(84)$ & $46(92)$ \\
\hline Amoxicillin (AMX) & 20 & $35(70)$ & $32(72)$ \\
\hline Streptomycin (S) & 30 & $43(86)$ & $46(92)$ \\
\hline Rifampicin (RD) & 20 & $40(80)$ & $46(92)$ \\
\hline Erythromycin (E) & 30 & $42(84)$ & $44(88)$ \\
\hline Chloramphenicol (CH) & 30 & $35(70)$ & $38(76)$ \\
\hline Ampicillin (APX) & 20 & $29(58)$ & $36(72)$ \\
\hline Levofloxacin (LEV) & 20 & $34(68)$ & $40(80)$ \\
\hline
\end{tabular}




\subsection{Antibiotic Resistance Phenotypes}

Resistance was observed to the antibiotics tested in 48 (48.0\%) of the isolates. The resistant isolates were distributed into various phenotypes as shown in Table 2. The commonest phenotypes for symptomatic isolates were APX-AMX-CH and AMX-APX-NB-CH-E at $11.5 \%$ each; and CH, CPX, CPX-LEV, APX-NB-E, AMX-APX-LEV, APX-S-NB-CH and AMX-APX-S-NB-CH-CPX-E-LEV$\mathrm{CN}$ at $7.7 \%$ each. For asymptomatic isolates, the commonest phenotypes were $\mathrm{CPX}(18.2 \%)$; and $\mathrm{CH}$, CPX-LEV, APX-AMX-RD-S-CH-CN and AMX-APX-RD-S-NB-CH-CPX-E-LEV at $9.1 \%$ each. The differences in the pattern of resistance between symptomatic and asymptomatic $S$. aureus isolates were insignificant $(\mathrm{p}>0.05)$.

\subsection{Multiple Antibiotic Resistance (MAR) Index}

Multiple antibiotic resistance (MAR), defined here as resistance to at least two antibiotics was observed in $38(79.2 \%)$ of the combined isolates distributed as follows: $23(88.5 \%)$ of symptomatic and $15(68.2 \%)$ of asymptomatic isolates. All the MAR isolates, whether from symptomatic or asymptomatic subjects, had indices $\geq 0.2$ as shown in Table 3 , suggesting that all of them originated from environments where antibiotics were freely abused/misused (Krumpermann, 1983). For symptomatic isolates, the commonest indices were $0.2(11.5 \%), 0.3(34.6 \%), 0.5(15.4 \%)$ and 0.9 (11.5\%); asymptomatic isolates had the commonest indices as $0.2(13.6 \%), 0.3(18.2 \%), 0.6(9.1 \%)$ and $0.9(9.1 \%)$.

Table2. Antibiotic resistant phenotypes of Staphylococcus aureus isolates from urine of symptomatic and asymptomatic subjects in Keffi, Nigeria

\begin{tabular}{|c|c|c|}
\hline \multirow[t]{2}{*}{ Antibiotic Resistant phenotypes } & \multicolumn{2}{|c|}{ Frequency (\%) Resistance phenotypes } \\
\hline & Symptomatic (26) & Asymptomatic (22) \\
\hline AMX & $1(3.8)$ & $1(4.5)$ \\
\hline $\mathrm{CH}$ & $2(7.7)$ & $2(9.1)$ \\
\hline CPX & $2(7.7)$ & $4(18.2)$ \\
\hline AMX-APX & $1(3.8)$ & $1(4.5)$ \\
\hline CPX-LEV & $2(7.7)$ & $2(9.1)$ \\
\hline APX-AMX-CH & $3(11.5)$ & $1(4.5)$ \\
\hline NB-CH-LEV & $1(3.8)$ & $1(4.5)$ \\
\hline APX-NB-E & $2(7.7)$ & $1(4.5)$ \\
\hline AMX-APX-LEV & $2(7.7)$ & $1(4.5)$ \\
\hline AMX-APX-NB & $1(3.8)$ & $0(0)$ \\
\hline APX-S-NB-CH & $2(7.7)$ & $1(4.5)$ \\
\hline AMX-APX-S-NB-LEV & $1(3.8)$ & $0(0)$ \\
\hline AMX-APX-NB-CH-E & $3(11.5)$ & $1(4.5)$ \\
\hline APX-AMX-RD-S-CH-CN & $1(3.8)$ & $2(9.1)$ \\
\hline AMX-APX-RD-S-NB-CH-E-CN & $1(3.8)$ & $1(4.5)$ \\
\hline AMX-APX-S-NB-CH-CPX-E-LEV-CN & $2(7.7)$ & $1(4.5)$ \\
\hline AMX-APX-RD-S-NB-CH-CPX-E-LEV & $1(3.8)$ & $2(9.1)$ \\
\hline
\end{tabular}

$\mathrm{CH}=$ Chloramphenicol; $\mathrm{CPX}=$ Ciprofloxacin; NB = Norfloxacin; $\mathrm{CN}=$ Gentamicin; $\mathrm{AMX}=$ Amoxicillin; $\mathrm{S}=$ Streptomycin; RD = Rifampicin; E = Erythromycin; APX = Ampicillin; LEV = Levofloxacin.

Table3. Multiple Antibiotic Resistance Index of Staphylococcus aureus isolates from urine of symptomatic and asymptomatic subjects in Keffi, Nigeria

\begin{tabular}{|c|c|c|c|c|}
\hline \multirow{2}{*}{$\begin{array}{l}\text { No. of antibiotics } \\
\text { MAR isolate is } \\
\text { resistant to (a) }\end{array}$} & \multirow{2}{*}{$\begin{array}{l}\text { No. of } \\
\text { antibiotics } \\
\text { tested (b) }\end{array}$} & \multirow{2}{*}{$\begin{array}{l}\text { MAR } \\
\text { indices }(\mathbf{a} / \mathbf{b})\end{array}$} & \multicolumn{2}{|l|}{ No. (\%) MAR isolates } \\
\hline & & & $\begin{array}{c}\text { Symptomatic } \\
(\mathrm{n}=26)\end{array}$ & $\begin{array}{l}\text { Asymptomatic } \\
(\mathbf{n}=22)\end{array}$ \\
\hline 9 & 10 & 0.9 & $3(11.5)$ & $2(9.1)$ \\
\hline 8 & 10 & 0.8 & $1(3.8)$ & $1(4.5)$ \\
\hline 7 & 10 & 0.7 & $0(0.0)$ & $0(0.0)$ \\
\hline 6 & 10 & 0.6 & $1(3.8)$ & $2(9.1)$ \\
\hline 5 & 10 & 0.5 & $4(15.4)$ & $1(4.5)$ \\
\hline 4 & 10 & 0.4 & $2(7.7)$ & $1(4.5)$ \\
\hline 3 & 10 & 0.3 & $9(34.6)$ & $4(18.2)$ \\
\hline 2 & 10 & 0.2 & $3(11.5)$ & $3(13.6)$ \\
\hline
\end{tabular}


Beta-Lactamase Production in Staphylococcus Aureus from Urine of Symptomatic and Asymptomatic Subjects in Keffi, Nigeria

\subsection{Minimum Inhibitory Concentration}

The MICs of amoxicillin against amoxicillin resistant $S$. aureus isolates from urine of symptomatic and asymptomatic subjects is as given in Figure 1. The MICs (extrapolated from Figure 1) of amoxicillin for $50 \%\left(\mathrm{MIC}_{50}\right)$ and $90 \%\left(\mathrm{MIC}_{90}\right)$ of S. aureus isolates from symptomatic subjects were $\leq 8.0 \mu \mathrm{g} / \mathrm{ml}$ and $\leq 16.0 \mu \mathrm{g} / \mathrm{ml}$ respectively; for asymptomatic isolates, the $\mathrm{MIC}_{50}$ and $\mathrm{MIC}_{90}$ of the isolates were $\leq 32.0 \mu \mathrm{g} / \mathrm{ml}$ and $\leq 64.0 \mu \mathrm{g} / \mathrm{ml}$ respectively. The differences in the MICs between symptomatic and asymptomatic isolates were insignificant $(\mathrm{p}>0.05)$.

\subsection{Beta-Lactamase Production}

Beta-lactamase was detected in 4(23.5\%) and 5(35.7\%) of amoxicillin resistant symptomatic and asymptomatic isolates respectively.

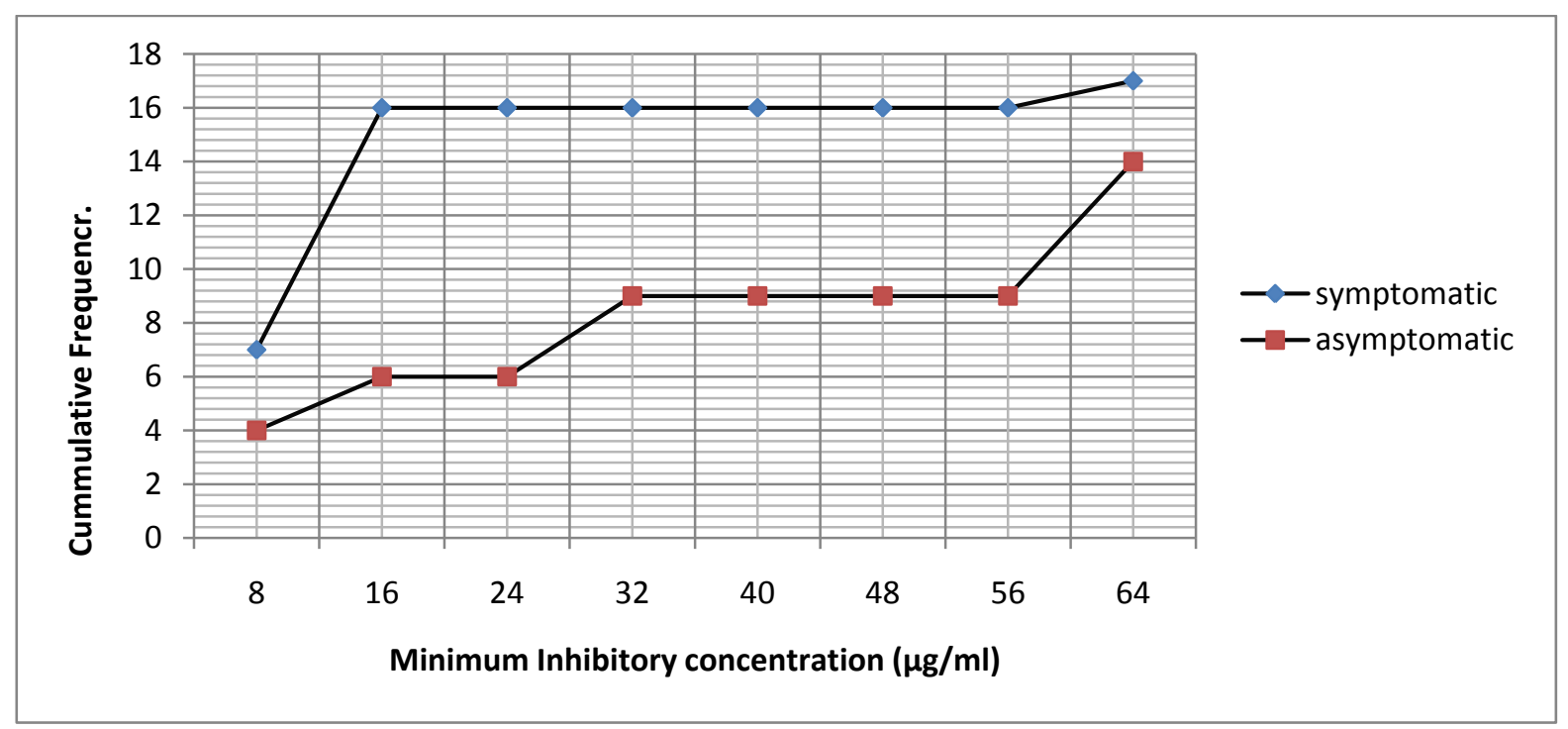

Figure1. Minimum Inhibitory Concentration of amoxicillin against amoxicillin resistant Staphylococcus aureus from urine of symptomatic and asymptomatic subjects in Keffi, Nigeria

\section{DisCUSSION}

Urinary tract infection (UTI) is a notorious problem in both the community and hospital practices, affecting people of all ages and gender (Adeleke and Olarinde, 2013). Infections caused by S. aureus pose serious threat in Health Care Institutions (Panlilio et al., 1992; NNIS, 2004). It is one of the most widely spread and virulent nosocomial pathogen and is usually resistant to multiple antibiotics making infections difficult to treat (Cooper et al., 2004).

This study observed a highly susceptibility of both symptomatic and asymptomatic $S$. aureus isolates from urine to the antibiotics tested. The observed high susceptibility of the isolates to chloramphenicol, ciprofloxacin and erythromycin agrees with an earlier study by Torimiro et al. (2013). The susceptibility to amoxicillin and gentamicin reported in this study is also in agreement with previous study conducted by other investigators (Shittu and Mandere, 1999; Olowu and Oyetunji, 2003; Akortha and Ibadin, 2008). The high susceptibility of most of the bacterial isolates to the antibiotics tested suggests misuse/abuse is minimal. For example, the discomfort of injections (e.g. gentamicin) is less likely reduce their frequently use or misuse (Ngwai et al., 2011); relatively higher cost of such antibiotics as ciprofloxacin in the environment under study creates affordability problem and reduces misuse. The observed high susceptibility of the $S$. aureus isolates from urine to amoxicillin and ampicillin was not expected; and is not in agreement with a previous study by Adeleke and Olarinde (2013), who reported high resistance rates by S. aureus against amoxicillin and ampicillin. The differences between the susceptibilities of symptomatic and asymptomatic isolates to antibiotics were insignificant.

The $\mathrm{MIC}_{50}$ and $\mathrm{MIC}_{90}$ values for the amoxicillin resistant symptomatic and asymptomatic $S$. aureus isolates was expectedly higher than the MIC breakpoint for amoxicillin described by CLSI (2014), suggesting higher level of resistance than thought from the diffusion susceptibility test results since MIC is more quantitative than normal zone of inhibition. 
Beta-lactamase production can be detected in the laboratory by three different methods namely: chromatogenic, acidometric and iodometric methods (Joris et al., 1994; Shrestha et al., 2014). This study showed that most of the $S$. aureus isolates resistant to amoxicillin were positive for betalactamase production as observed in a previous study (Adeleke and Olarinde, 2013). The percentage beta-lactamase producing S. aureus isolates is lower than other earlier reports (Kesah et al., 1997, Akindele et al., 2010). Beta-lactamases are a family of enzymes produced by many bacteria that inactivates beta-lactam antibiotics by opening the beta-lactam ring (Kok et al., 2010). Beta-lactamases are enzymes that are responsible for many failures of antimicrobial therapy by the hydrolysis of betalactam ring of these antibiotics (Bush, 1989). The spread of beta-lactamase genes had been enhanced by their integration within mobile genetic elements such as plasmids and transposon which facilitate the rapid transfer of genetic materials between microbes (Wilke et al., 2005). It is surprising that in this study more than half of the amoxicillin resistant strains were negative for beta lactamase production, yet were resistant to beta-lactamases. This suggests that beta-lactamase production is only a part of factors accounting for resistance in these bacteria, indicating that other mechanisms of resistance may play a major role as well. Consequently, further studies on molecular characterization of beta-lactamase production by the $S$. aureus isolates as well as other mechanisms of resistance to beta-lactam demonstrated by these isolates from urine of symptomatic and asymptomatic subjects in Keffi, Nigeria should be carried out.

\section{REFERENCES}

Atata, R..F., Ibrahim, Y.K.E., Giwa, A. and Akanbi II, A.A. (2013). Antibiotics resistance profile of bacterial isolates from surgical site and hospital environment in a University teaching hospital in Nigeria. Journal of Medicine and Medical Sciences 4(4):181-187.

Adeleke, O.E. and Olarinde J.D. (2013). Antibiotic susceptibility profile of Urinary Tract Infection isolates of S. aureus. New York Science Journal 6 (12).

Akindele A.A., Adewuyi, I.K., Adefioye, O.A., Adedokun, S.A and Olaolu, A.O. (2010). Antibiogram and beta-lactamase production of $S$. aureus isolates from different Human Clinical specimens in a Tertiary Health Institution in Ile-ife, Nigeria. American-Eurasian Journal of Scientific Research. 5 (4):230-233.

Akortha, E.E. and Ibadin, O.K. (2008). Incidence and antibiotic susceptibility pattern of Staphylococcus aureus amongst patients with urinary tract infection in U.B.T.H. Benin city, Nigeria. African Journal of Biotechnology 7 (11):1637-1640.

Al-jumaily E.F., Muhammad D.A. and Khanaka H.H. (2012). Molecular epidemiology and antibiotic susceptibility patterns of clinical strains of methicillin resistant $S$. aureus in Sulaimani City-Iraq. Global Advanced Research Journal of Microbiology. 6:81-89.

Akwa, V.L., Bimbol, N.L., Samaila, K.L. and Macus, N.D. (2007). Geography Perspective of Nassarawa State. Onaivi Printing and Publishing Company, Keffi, Nigeria. Pp: 3-5.

Bush, K. (1989). Characterization of $\beta$-lactamases. Antimicrobial Agents and Chemotherapy. 33:259263.

Cheesebrough, M. (2006). Medical Laboratory Manual for TropicalCountries. Cambridge: Cambridge University Press, Pp. 49-97.

CLSI (2014). Performance Standards for Antimicrobial SusceptibilityTesting: 24th Informational Supplement M100-S24. Wagne, PA: Clinicaland Laboratory Standards Institute.

Cooper, B.S., Medley, G.F., Stone, S.P., Kibb1er, C.C., Cookson, B.D., Roberts, J.A., Duckworth, G., Lai, R. and Ebrahim, S. (2004). Methicillin-resistant Staphylococcus aureus in hospitals and the community: Stealth dynamics and control catastrophes. Proceedings of the National Academy of Sciences (PNAS) of the USA. 101(27):10,223-10,228.

Hugo, W.B. and Russel, A.D. (1986). Pharmaceutical Microbiology. $3^{\text {rd }}$ Edition. Blackwell Scientific Publications, London.

Joris, B., Hardt, K. and Ghuysen, G.M. (1994). Induction of $\beta$-lactamase and low affinity Penicillin Binding Protein 2' synthesis in Gram- positive bacteria. Bacterial Cell Wall. Elsevier Science, New York, 505-515.

Kok, F.K., Lisa, S. and Kalai, M. (2010). Beta-lactam antibiotics: From antibiotics to resistance and bacteriology. 118(1):1-36 
Beta-Lactamase Production in Staphylococcus Aureus from Urine of Symptomatic and Asymptomatic Subjects in Keffi, Nigeria

National Nosocomial Infections Surveillance (NNIS). (2004). NNIS System Report, Data Summary from January 1992 through June 2004, issued October 2004. American Journal of Infection Control 32(8):470-485.

Ngwai, Y.B., Ezenwa, F.C. and Ngadda N. (2011). Contamination of Nigerian currency notes by Escherichia coli in Nasarawa State University, Keffi, Nigeria. Asian Journal of Pharmaceutical and Health Science 1(4): 1(4):163-166.

Olowe, O.A., Eniola, K.I.T., Olowe, R.A. and Olayemi, A.B. (2007). Antimicrobial Susceptibilty and Beta-lactamase detection in MRSA in Osogbo, SW Nigeria. Nature and Science 5(3):44-48.

Olowu, W.A. and Oyetunji, T.G. (2003). Nosocomial significant bacteremia: prevalence and patterns of bacterial pathogens among children hospitalized for non-infecting urinary tract disease. West African Journal of Medicine 22 (1):72-74.

Panlilio, A.L., Culver, D.H., Gaynes, R.P., Banerjee, S., Henderson, T.S., Tolson, J.S. and Martone, W.J. (1992). Methicillin-resistant Staphylococcus aureus in U.S hospitals, 1975-1991. Infection Control and Hospital Epidemiology 13(10):582-586.

Pantosti A., Sanchini A. and Monaco, M. (2007). Mechanisms of antibiotic resistance in Staphylococcus aureus. Future Microbiology 2(3):323-334.

Salem-Bekhit, M.M. (2014). Phenotypic and genotypic characterization of nosocomial isolates of $S$. aureus with reference to Methicillin Resistance. Tropical Journal of Pharmaceutical Research. 13(8):1239-1246.

Shittu, S.O. and Mandere, M.U. (1999). Asymptomatic bacteriuria in antenatal patients in A.B.U.T.H Zaria. Tropical of Journal Obstetrics and Gynecology 16(1):41.

Shrestha, B. and Rana, S.S. (2014). Comparative study of three beta-lactamase test methods in $S$. aureus isolated from two Nepalese Hospitals. Open Journal of Clinical Diagnosis 4:47-52.

Torimiro, N., Moshood, A.A. and Eyiolawi, S.A. (2013). Analysis of $\beta$-lactamase production and antibiotics resistance in Staphylococcus aureus strains. Journal of Infectious Diseases and Immunity 5(3):24-28.

Wilke, M.S., Lovering, A.L., Strynadka, C.J.N. (2005). $\beta$-lactam antibiotic resistance: A Current Structural perspective. Current Opinion in Microbiology 8:525-533.

Krumpermann, P.H. (1983). Multiple Antibiotics Resistance Indexing of Escherichia coli to Identify High Risks Sources of FecalContamination of Foods. Applied and Environmental Microbiology, 46:165-170. 